Review

\title{
Study and Therapeutic Progress on Intracranial Serpentine Aneurysms
}

\author{
Kan $\mathrm{Xu}^{1^{*}}$, Tiecheng $\mathrm{Yu}^{2^{*}}$, Yunbao Guo ${ }^{1}$, Jinlu $\mathrm{Yu}^{1 凶}$ \\ 1. Department of Neurosurgery, First Hospital of Jilin University, Changchun, 130021, P.R. China; \\ 2. Department of Orthopedics, First Hospital of Jilin University, Changchun, 130021, P.R. China. \\ * Kan $\mathrm{Xu}$ and Tiecheng Yu contributed equally to the work. \\ $\triangle$ Corresponding author: Jinlu Yu, Department of Neurosurgery, First Hospital of Jilin University, 71 Xinmin Avenue, Changchun 130021, China. E-mail: \\ jinluyu@hotmail.com.
}

(1) Ivyspring International Publisher. Reproduction is permitted for personal, noncommercial use, provided that the article is in whole, unmodified, and properly cited. See http://ivyspring.com/terms for terms and conditions.

Received: 2016.01.11; Accepted: 2016.05.08; Published: 2016.05.26

\begin{abstract}
An intracranial serpentine aneurysm (SA) is a clinically rare entity, and very few multi-case studies on SA have been published. The present study reviewed the relevant literature available on PubMed. The studied information included the formation mechanism and natural history of SA as well as its clinical manifestation, imaging characteristics, and current treatments. After reviewing the literature, we conclude that intracranial SA can be managed surgically and by endovascular embolization, but the degree of blood flow in normal brain tissue distal to the SA must be evaluated. A balloon occlusion test (BOT) or cross compression test is recommended for this evaluation. If the collateral circulation is sufficiently compensatory, direct excision or embolization can be performed. However, if the compensatory collateral circulation is poor, a bypass surgery is necessary. Satisfactory results can be achieved in the majority of SA patients after treatment. However, the size of the aneurysm may increase in some patients after endovascular treatment. Special attention should be paid to cases exhibiting a significant mass effect to avoid subsequent SA excision due to an intolerable mass effect. Satisfactory results can be achieved with careful treatment of SA.
\end{abstract}

Key words: intracranial serpentine aneurysm, natural history, surgical treatment, progress.

\section{Introduction}

An intracranial serpentine aneurysm (SA) is an uncommon clinical entity, and few multi-case studies have been published. This study reviewed the relevant literature available in PubMed. The term "serpentine aneurysm" was first used by Segal and McLaurin, in 1977, to describe a subcategory of partially thrombosed giant aneurysms [1]. The distinctive neuroimaging features of these aneurysms are large size $(>25 \mathrm{~mm})$ and a twisted vascular course within the aneurysm with multiple entrance and exit points. These non-endothelialized, intrathrombotic channels enable blood flow to distal branches of the artery from which the aneurysm originates, thus supplying vital areas of the brain parenchyma. SAs account for less than $0.1 \%$ of all intracranial aneurysms and $17.6 \%$ of giant aneurysms [2]. SAs are more common in adults. Our literature review located several reported cases in children, and some of these cases may have been associated with arterial developmental abnormalities [3].

\section{Formation mechanism of SA}

The SA formation mechanism remains unclear, but several hypotheses have been proposed.

(1) SAs might be caused by the Coanda effect induced by a saccular aneurysm. In 1978, Fodstad et al. reported a case of intracavernous aneurysm. In this case, thrombi were formed in the aneurysm after ligation of the carotid artery but did not completely occlude the aneurysm. Therefore, an SA occurred 6 months later, and blood was observed to pass through the SA; this case suggested that an SA can easily develop in cases of incomplete thrombus formation and continuing blood flow in a large aneurysm [4]. This effect would primarily occur because of a decrease in blood flow, producing hemodynamic conditions suitable for the 
Coanda effect, in which hemodynamic perturbations can lead to an SA.

SAs can easily occur in the middle cerebral artery (MCA), an effect that may be related to a lower force of jet-pattern blood flow, causing the formation of a thrombus. In 2009, Christiano et al. reported that giant SAs most commonly occur in the MCA (50\%), followed by the posterior cerebral artery (18\%), vertebral artery or vertebrobasilar junction (15\%), internal carotid artery (13\%), and, less commonly, the distal anterior cerebral artery (3\%). This distribution may stem from the fact that no dural or cranial surfaces limit expansion of the aneurysm in these locations; the Coanda effect can also occur easily and contribute to SA formation in these vessels [5-8].

(2) SAs might originate from fusiform aneurysms. It has been suggested that SAs evolve from fusiform aneurysms. For example, in 2012, Senbokuya et al. reported a case of distal anterior cerebral artery aneurysm that evolved into an SA after 5 months. This effect may be caused by repeated intramural bleeds in the fusiform aneurysm [9]. In 1992, Suzuki et al. reviewed the literature and found that aneurysms evolved from fusiform or simple large aneurysms to SAs in 12 of 39 cases, with these evolutions taking between 26 days and 5 years [10]. It has been hypothesized that spontaneous fusiform MCA aneurysms may develop as a result of arterial dissection with intramural hemorrhage between the intima and the media [11]. For example, in 2008, Verny et al. reported a case of an MCA dissecting aneurysm that evolved into SA in 11 years [12]. This case supports the notion that a dissection can trigger a pathological process that leads to the formation of an SA [13].

(3) SAs can originate from dolichoectatic aneurysms. It has recently been hypothesized that continuous growth of a dolichoectatic aneurysm can lead to SA formation. For example, Vishteh et al. reported a case in 1999 of a dolichoectatic aneurysm that evolved into a giant SA during a 7-year follow-up [14]. Furthermore, if the size of a dolichoectatic aneurysm gradually enlarges due to intra-aneurysm thrombosis, SA may occur [2].

(4) SA occurrence may be associated with abnormalities in the blood vessel wall. For example, in 1997, Bakac et al. reported a case of MCA SA. A large aneurysm developed in the region distal to the original SA 4 years after an extracranial-intracranial bypass [15]. SA is common in the MCA, and a giant aneurysm is also prone to occur in the MCA. These facts indicate that a certain structure of the MCA may relate to the formation of SA [16]. In addition, in 1988, Terada et al. reported a case of giant SA of the distal vertebral artery in a 50-year-old male with 8 years of hemodialysis and a history of hypertension and hyperlipidemia. This report suggested that the roles of hemodialysis and atherosclerosis on SA formation could not be excluded [17]. SA accompanied by AIDS has also been reported. In 2008, Mahadevan et al. reported a case of HIV infection in a child with the occurrence of a vertebral basilar artery SA [18].

Thus, the origin of SA is complex. The key factors are that the size of the aneurysm gradually increases and that an intra-aneurysm thrombus gradually forms with active blood flow.

\section{Natural history of SA}

The natural history of SA remains unknown and unpredictable.

(1) Progressive mass effect or rupture. Because giant SAs have a $1-4 \mathrm{~mm}$ thick fibrous wall, they contain small vessels that are similar to the vasa vasorum of large blood vessels. Thus, giant SAs are less likely to rupture and usually present with signs of a mass effect $[1,19]$. A progressive mass effect is a feature of SA. In 1981, Patel et al. reported a case of MCA SA, the size of which significantly increased over 5 years [20]. Hemorrhage may occur, and hemorrhaging from a ruptured aneurysm causes intracerebral hematoma because the SA is located in brain tissue (Figure 1). Therefore, subarachnoid hemorrhage (SAH) is not considered to be a common presentation of giant SAs. In 1992, Suzuki et al. reported in his review that $28 \%$ of giant SA patients initially presented with SAH [10].

(2) Spontaneous occlusion. A small subset of SAs may spontaneously become occluded. In 2006, Sari et al. reported a case of MCA SA that exhibited acute complete occlusion of the vascular channel 13 days after the initial angiography; 3 years later, angiography showed no serpentine channel [21]. In 1995, Aletich et al. reported a case of giant MCA SA. An angiogram performed at 8 months and an MRI performed at 1 year demonstrated a persistent thrombosed aneurysm [22]. Spontaneous occlusion of an SA is considered to result from slow blood flow and thrombus formation. In addition, contrast-induced thrombosis may also be considered a possible cause of acute thrombosis [23]. SA occlusion has also been reported to result from neoangiogenesis. In 2012, McLaughlin et al. reported a case of distal MCA SA that spontaneously occluded 3 days after definite diagnosis. One month later, superselective digital subtraction angiography (DSA) revealed the presence of numerous neovessels [24].

Therefore, the natural history of SA can manifest as a progressive mass effect, hemorrhage from rupture, and spontaneous occlusion. Of these, the development of a mass effect caused by gradual growth of the aneurysm is the most common, while 
spontaneous occlusion is extremely rare.

\section{Clinical manifestations}

The age of onset for SA is similar to that for intracranial aneurysms [25]. Most SA patients are male, and the peak age of occurrence is from 30 to 60 years $[8,22]$. An SA can yield a variety of symptoms. In 1995, Aletich summarized the symptoms from 29 of 33 cases of giant SA in his review, finding that headache was present in $72 \%$ (21), hemiparesis or hemiplegia in 55\% (16), visual deficits in $48 \%$ (14), cranial nerve palsy in $31 \%$ (9), and seizures in $21 \%$ (6) [22]. However, SAH was reported in 4\%-23.5\% [26].

(1) Mass effect. Headache is the first sign of a mass effect and is the most common clinical manifestation of SA [26]. In 2012, Senboku et al. reported a case of distal anterior cerebral artery SA with headache. The SA continued growing and became larger over a 5-month period of non-intervention; a very severe headache resulted in this case [9]. Other than headache, SA mass effects more commonly manifest as neurological deficits, such as compression symptoms of the brainstem, as reported by Kalani in 2014 [27]. In addition, SA can compress the optic nerve and cause visual impairment, as reported by Krafft in 2015 in a case of SA in the sellar region [28]. The large size of SAs, their irregular shape, significant mass effect, and surrounding brain tissue edema due
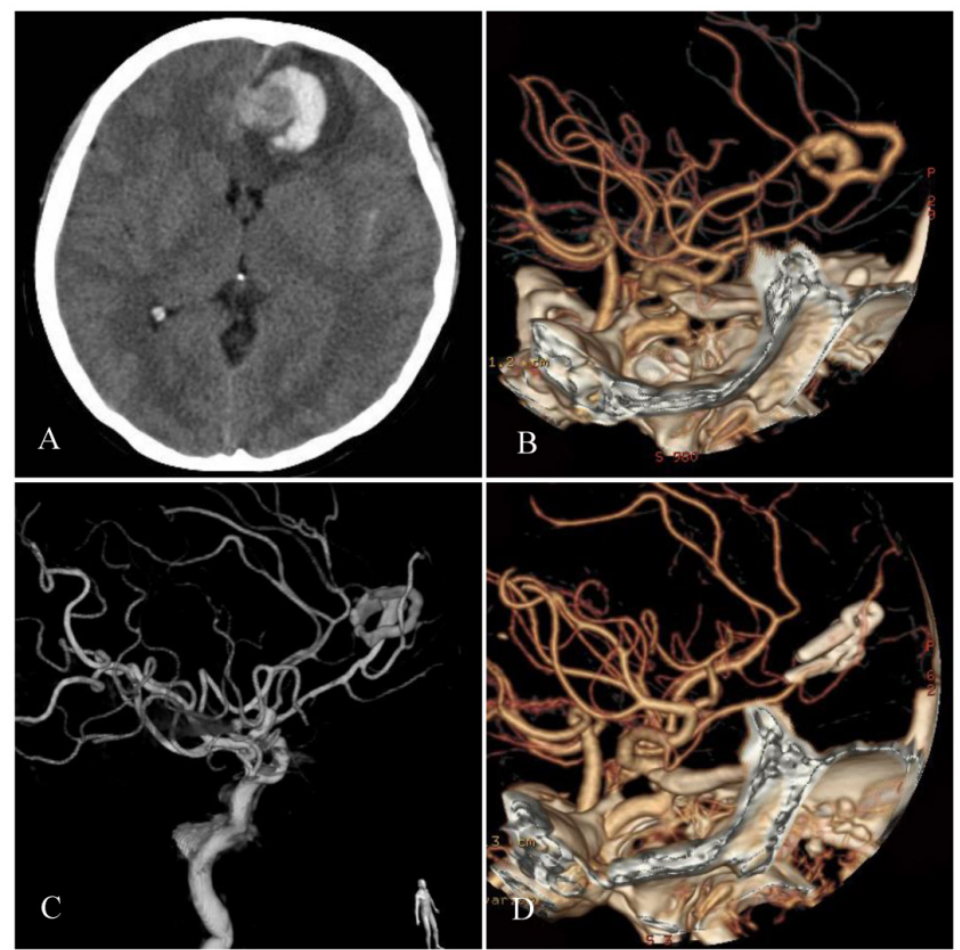

Figure 1: Typical features of SA. A: Head CT shows left frontal lobe lesions in which the higher density circle next to a longitudinal fissure is noted. A lateral, crescent-shaped, high-density hemorrhage was present. B-C: Head CTA and DSA reveal an SA of the distal-anterior cerebral artery. D: Postoperative CTA shows that the SA has been removed; multiple aneurysm clips are observed. to compression are also similar to what is observed in a brain tumor. Therefore, an SA can be occasionally misdiagnosed as cancer [29]. In 1988, Belec et al. reported a case of posterior cerebral artery SA that was misdiagnosed as a left lateral hypothalamic tumor [30].

(2) Stroke. SA can also present with hemorrhage or ischemia. It is not uncommon that ruptured SAs manifest as intracerebral hematomas due to their location in the brain (Figure 1). By contrast, SAH is not considered a common presentation of giant SAs. In 1992, a review by Suzuki et al. reported that only $28 \%$ of patients with giant SA initially presented with SAH [10]. Meanwhile, SA can also manifest as ischemia due to distal emboli, the occlusion of side branches, or direct flow impairment. The outflow from giant SAs feeds distal cortical vessels, and occlusion or narrowing of these vessels results in stroke [8].

(3) Rare manifestations. In addition to the above-mentioned manifestations, an SA may also cause various complex symptoms according to its location. For example, in 2013, Kobylecki et al. reported personality disorders in a case of anterior cerebral artery SA, in which the aneurysm was located in the frontal lobe and involved the corpus callosum. Dementia related to the frontal and temporal lobe was also present [31]. Amnesia can also be present, as reported by Tsuang et al. in 2010. In this case, the SA was present in the MCA [32]. Some MCA SAs may cause seizures, as reported in 1994 by Horowitz et al. [33].

\section{Imaging examination}

Intracranial SAs can include thrombi at various stages of formation that exhibit various intensities or signal characteristics on CT or MRI. Edema of the surrounding brain tissue due to compression is also present, similar to in a brain tumor. Contrast-enhanced CT or MRI scans show a so-called "target sign". Thrombi in SAs may present with a tumor-like intensity and can be an additional feature of SAs [32].

A vascular imaging study can provide more details on SAs. For example, CT angiography (CTA) may reveal the outline of a large aneurysm, an enhanced aneurysm wall and an image of its circuitous path [31]. DSA is the gold standard for the diagnosis of SA and can clearly reveal the SA shape. However, the drawback of DSA is that the aneurysm wall is not visible [27]. The diagnostic accuracy for SA by magnetic resonance angiography (MRA) is 
similar to that obtained by CTA $[3,34]$.

In imaging studies, it is necessary to differentiate SA from dolichoectatic aneurysm. However, dolichoectatic aneurysms are more common in the basilar artery. One difference is that thrombi are less common in dolichoectatic aneurysms, which manifest as a simple, calcified, distended vessel wall. A mass effect is also uncommon in dolichoectatic aneurysms, although ischemia is observed [35].

\section{Treatment}

Aggressive surgical treatment is recommended in SA, given that conservative treatment often leads to continued growth of the aneurysm [10, 18]. The treatment of SA should eliminate the patent vascular channel, halt the growth of the aneurysm, and relieve the adjacent mass effect; however, because the outflow pathways supply the normal brain parenchyma, simple proximal occlusion or trapping without revascularization may have a disastrous outcome. It has been reported that the complication rate of direct surgical clipping is 30-35\% [36-38]. Hence, a balloon occlusion test (BOT) or cross compression test should be used for this assessment. If compensatory collateral circulation distal to the SA is poor, a bypass surgery is required.

\section{(1) Craniotomy}

Craniotomy includes the direct resection of the SA without bypass surgery, SA resection with concomitant bypass surgery, or proximal/distal occlusion of the SA with concomitant bypass surgery. Only an isolated bypass surgery was necessary to successfully treat a case of MCA SA, as reported by Suzuki et al. in 1992. In this case, the SA was occluded after an isolated superficial temporal artery (STA)-MCA bypass surgery. The occlusion was considered to result from hemodynamic changes in which distal blood flow caused a decrease in the intra-SA blood flow and eventual occlusion [10]. However, most SAs require further treatment after bypass surgery. In 2015, Pavesi et al. reviewed 31 cases of SA with surgical treatment and found that cerebral blood flow reconstruction combined with surgical clipping or resection is the best treatment. Intraoperative monitoring was also advocated, e.g., intraoperative monitoring of motor evoked potentials (MEPs) or intraoperative indocyanine-green angiography [39].

(1) Direct resection. This is the most simple and practical approach and can resolve the mass effect. In 2012, Senbokuya et al. reported a case of a distal cerebral artery SA. Compensating collateral circulation of the pia mater was confirmed by BOT, and the aneurysm was directly resected [9]. Unvisualized vessels distal to the SA can, in some cases, indicate that branches from the pia mater may compensate for distal blood flow. SA can directly be resected if this is the case. In 1982, Fukamachi et al. reported a case of SA from the P2 segment of the posterior cerebral artery. The vessels distal to the SA were not visualized on angiography. The SA was separated and resected directly, and a 3-month follow-up showed a good prognosis [40]. The details of these case reviews are provided in Table 1.

Table 1. Data of direct excision or endovascular embolization.

\begin{tabular}{|c|c|c|c|c|c|c|}
\hline No. & Authors/Year & Age/Sex & Location & Treatment & Follow-up & Prognosis \\
\hline 1 & Krafft/2015[28] & $71 / \mathrm{F}$ & Anterior cerebral artery & Direct occlusion after a cross compression test & 14 months & Favorable \\
\hline 2 & Senbokuya/2012[9] & $38 / \mathrm{M}$ & Distal anterior cerebral artery & Direct resection after a BOT & 2 years & Favorable \\
\hline \multirow[t]{3}{*}{3} & Van/2008[53] & $16 / \mathrm{M}$ & Distal anterior cerebral artery & Direct occlusion after a BOT & 2 months & Favorable \\
\hline & & $68 / \mathrm{F}$ & MCA & Direct occlusion after a BOT & 3 months & Favorable \\
\hline & & $51 / \mathrm{F}$ & Anterior cerebral artery & $\begin{array}{l}\text { Direct occlusion after a BOT; Elimination of the mass } \\
\text { effect by surgical resection }\end{array}$ & 10 months & Favorable \\
\hline \multirow[t]{5}{*}{4} & Xianli/2007[47] & $43 / \mathrm{M}$ & P2-posterior cerebral artery & Direct occlusion & 8 months & Favorable \\
\hline & & $48 / \mathrm{M}$ & P2-posterior cerebral artery & Direct occlusion & 4 months & Favorable \\
\hline & & $31 / \mathrm{M}$ & P2-posterior cerebral artery & Direct occlusion & 7 months & Favorable \\
\hline & & $4 / \mathrm{M}$ & P1-posterior cerebral artery & Direct occlusion & 3 years & Favorable \\
\hline & & $9 / \mathrm{M}$ & Distal MCA & Direct occlusion & 3 months & Favorable \\
\hline 5 & Zicherman/2004[49] & $21 / \mathrm{M}$ & Superior cerebellar artery & Direct occlusion & 2 months & Favorable \\
\hline 6 & Pany/2004[50] & $26 / \mathrm{M}$ & MCA & Direct occlusion & 1 week & Favorable \\
\hline 7 & Fanning/2003[5] & $30 / \mathrm{M}$ & Left intra-cavernous sinus & Carotid ligation & 3 months & Favorable \\
\hline \multirow[t]{2}{*}{8} & Coley/2002[52] & $43 / \mathrm{M}$ & P2-posterior cerebral artery & Direct occlusion & 6 months & Favorable \\
\hline & & $33 / \mathrm{M}$ & P2-posterior cerebral artery & Direct occlusion & 10 months & Favorable \\
\hline \multirow[t]{2}{*}{9} & Otsuka/2001[48] & $48 / \mathrm{M}$ & $\begin{array}{l}\text { Distal-internal carotid artery } \\
\text { involving A1 }\end{array}$ & Direct occlusion after a proximal cross compression test & 3 months & Favorable \\
\hline & & $10 / \mathrm{M}$ & Vertebral artery & Direct occlusion after a proximal cross compression test & 4 months & Favorable \\
\hline \multirow[t]{2}{*}{10} & Aletich/1995[22] & $34 / \mathrm{F}$ & Distal MCA & Direct occlusion with a coil and glue & 1 year & Favorable \\
\hline & & $44 / \mathrm{M}$ & Vertebral artery & $\begin{array}{l}\text { Occluding vertebral artery after a proximal cross } \\
\text { compression test }\end{array}$ & -- & Favorable \\
\hline 11 & Fukamachi/1982[40] & $48 / \mathrm{F}$ & P2-posterior cerebral artery & Direct resection & 3 months & Favorable \\
\hline 12 & Lee/1999[54] & $18 / \mathrm{F}$ & P2-posterior cerebral artery & Direct resection & -- & Favorable \\
\hline
\end{tabular}


(2) SA resection plus revascularization. This is the best approach for SA treatment. In 2012, Moon et al. reported a case of SA from the A2-A3 segment of the anterior cerebral artery. SA resection and ipsilateral-to-contralateral A3 revascularization were performed, and a favorable outcome was achieved at the 3-month follow-up [41]. In 2015, Pavesi et al. reported a case of MCA SA in which preoperative coiling embolization was performed to reduce blood flow to the SA. The SA was then resected, and an end-to-end vascular anastomosis was performed. A good recovery was observed at the 1-year follow-up, except for mild hyposthenia of the left lower extremity [39]. In 1993, Greene et al. treated a case of MCA SA by (i) anastomosis of the STA to the distal artery of the SA and (ii) aneurysm resection. A favorable prognosis was achieved in this case [42].

After a literature review, we found that a low-flow bypass was adequate in the majority of SA cases. In 2010, Lee et al. reported a case of MCA SA in which the distal end of the SA was only attached to a branch of the MCA; a low-flow graft bypass surgery was performed, followed by aneurysm resection. A 2-year follow-up revealed a good prognosis [38]. Occasionally, medium-flow bypass surgery is required. For example, this type of bypass was used to treat an MCA SA, as described by Tsuang et al. in 2010. In this case, a bypass was made from the left superior thyroid artery to the M2 segment of the MCA, with a radial artery graft; the aneurysm was subsequently excised [32]. High-flow bypass surgery was reported by González-Darder et al. in 2011. In this case of an MCA SA, a high-flow bypass surgery from the petrous internal carotid artery to the M1 segment was performed using the great saphenous vein as a graft. The SA was subsequently excised, and a 6-month follow-up showed a favorable prognosis [43]. The details of these cases are given in Table 2.

(3) Bypass combined with occlusion of the SA distal outflow pathway: STA-MCA bypass surgery can be performed followed by clipping of the distal outflow pathway of the SA, and a favorable outcome can be achieved without SA excision. Such a procedure is used given that slowing or stopping blood flow after clipping the outflow pathway can induce the formation of thrombus within the SA.

Abiko et al. in 2009 reported a typical case of MCA SA in which an intra-SA thrombus formed within 1 hour of an STA-to-MCA anastomosis [44]. In 1994, Horowitz et al. reported a case of MCA aneurysm in which a retrograde thrombosis formed after clipping an STA-MCA anastomosis at the distal SA, which was done because of operating space limitations. An 18-month follow-up showed a good prognosis [33]. In 1995, Aletich et al. reported a case of MCA SA in which an STA-MCA anastomosis and occlusion of the outflow pathway were performed. Aneurysm thrombosis occurred, but the proximal end of the aneurysm remained patent 9 days after surgery. Thus, occlusion of the proximal aneurysm and partial resection were performed [22].

Table 2. Data of SA resection after surgical bypass.

\begin{tabular}{|c|c|c|c|c|c|c|}
\hline No. & Authors/Year & Age/Sex & Location & Treatment & Follow-up & Prognosis \\
\hline 1 & Pavesi/2015[39] & $66 / \mathrm{F}$ & MCA & $\begin{array}{l}\text { Partial aneurysm occlusion to reduce bleeding during } \\
\text { surgery; resection of the SA } 2 \text { days later plus end-to-end } \\
\text { anastomosis }\end{array}$ & $\begin{array}{l}\text { Left } \\
\text { hemiplegia } 2 \\
\text { days after } \\
\text { surgery. }\end{array}$ & $\begin{array}{l}\text { Good recovery } 1 \text { year after } \\
\text { surgery with the exception of } \\
\text { mild hyposthenia in the left } \\
\text { lower extremity }\end{array}$ \\
\hline 2 & Moon/2012[41] & $49 / \mathrm{F}$ & $\begin{array}{l}\text { Distal anterior } \\
\text { cerebral artery }\end{array}$ & Resection after $\mathrm{A} 3-\mathrm{A} 3$ bypass & 3 months & Favorable \\
\hline 3 & $\begin{array}{l}\text { González-Darder } \\
\text { /2011[43] }\end{array}$ & $35 / F$ & MCA & $\begin{array}{l}\text { High-flow bypass with anastomosis of the saphenous } \\
\text { vein to M1 }\end{array}$ & 6 months & Favorable \\
\hline 4 & Lee/2010[38] & $43 / \mathrm{F}$ & MCA & $\begin{array}{l}\text { SA resection after anastomosis of the STA to the } \\
\text { M4-MCA }\end{array}$ & 2 years & Favorable \\
\hline 5 & Tsuang/2010[32] & $55 / \mathrm{F}$ & MCA & $\begin{array}{l}\text { Superior thyroid artery to the } \mathrm{M} 2 \text { segment of the MCA } \\
\text { with a radial artery graft; SA resection }\end{array}$ & 1 week & Favorable \\
\hline 6 & Bakac/1997[15] & $17 / \mathrm{F}$ & MCA & SA resection after EC-IC bypass & 4 years & $\begin{array}{l}\text { Newly occurred aneurysm } \\
\text { from the distal MCA }\end{array}$ \\
\hline 7 & Greene/1993 [42] & $14 / \mathrm{M}$ & MCA & $\begin{array}{l}\text { Phase I: anastomosis of the STA to the distal SA; Phase } \\
\text { II: aneurysm resection. }\end{array}$ & 6 months & Favorable \\
\hline 8 & Abiko/2009[44] & $56 / \mathrm{M}$ & MCA & $\begin{array}{l}\text { Outflow channel occlusion after STA-SCA bypass, } \\
\text { followed by SA resection }\end{array}$ & -- & Favorable \\
\hline 9 & Aletich/1995[22] & $14 / \mathrm{M}$ & MCA & $\begin{array}{l}\text { Outflow channel occlusion following STA-SCA bypass. } \\
\text { Surgical occlusion of the proximal aneurysm after } 9 \\
\text { days, followed by partial SA resection }\end{array}$ & -- & Favorable \\
\hline
\end{tabular}


Table 3. Data on the occlusion of aneurysm inflow or outflow channels after bypass.

\begin{tabular}{|c|c|c|c|c|c|c|}
\hline No. & Authors/Year & Age/Sex & Location & Treatment & Follow-up & Prognosis \\
\hline 1 & Kalani/2014[27] & $45 / \mathrm{M}$ & Upper basilar artery & Outflow channel occlusion after STA-SCA bypass & 20 years & Favorable \\
\hline 2 & Amin-Hanjani/2006[45] & $14 / \mathrm{M}$ & MCA & Inflow channel occlusion after STA-MCA bypass & 13 years & Favorable \\
\hline \multirow[t]{2}{*}{3} & Anshun/2000[26] & $27 / \mathrm{M}$ & MCA & Carotid ligation after STA-MCA bypass & 2 years & Favorable \\
\hline & & $38 / \mathrm{M}$ & $\begin{array}{l}\text { From the petrous portion of the } \\
\text { internal carotid artery to the MCA }\end{array}$ & Carotid ligation after STA-MCA bypass & 18 months & Favorable \\
\hline 4 & Aletich/1995[22] & $20 / \mathrm{M}$ & Clinoid segment of the ICA & Carotid ligation after STA-MCA bypass & 1 year & Favorable \\
\hline 5 & Horowitz/1994[33] & $19 / \mathrm{M}$ & MCA & Outflow channel occlusion after STA-SCA bypass & 18 months & Favorable \\
\hline 6 & Isla/1994[55] & $37 / \mathrm{M}$ & MCA & Carotid ligation after STA-MCA bypass & 2 years & Recurrence \\
\hline 7 & Yoshimura/1994[56]。 & $35 / \mathrm{M}$ & ICA and MCA & Carotid ligation after STA-MCA bypass & 10 years & Recurrence \\
\hline
\end{tabular}

In our opinion, an SA can be completely occluded over a longer period. In 2014, Kalani et al. reported a case of SA at the distal end of the basilar artery that presented with compressive symptoms of the brainstem. The basilar artery was occluded by clipping after bypass of the superior cerebellar artery to the STA, without perforating the branches that were under the superior cerebellar artery. At the 3-year follow-up, the symptoms were resolved, and an imaging study showed a patent bypass and no evidence of an aneurysm. The 20-year follow-up confirmed this good prognosis [27]. The details of these cases are given in Table 3.

(4) Bypass combined with occlusion of the SA inflow pathway: The occlusion of the SA inflow pathway after bypass can also achieve a good therapeutic effect. In 2006, Amin-Hanjani et al. reported a case of MCA SA in which only a proximal occlusion was performed after STA-to-MCA anastomosis to avoid damage to the MCA perforating branches. A good prognosis was reported at the 13-year follow-up [45]. Some cases are unique, e.g., when the proximal portion of the aneurysm cannot be occluded, the occlusion of the internal carotid artery can be an alternative method. In 1995, Aletich et al. reported a case of supraclinoid segment SA. In this case, an STA-to-MCA bypass was followed by occlusion of the internal carotid artery. These procedures were performed because occlusion of the proximal portion of the SA or of the inflow pathway can induce the formation of a retrograde thrombus. A satisfactory outcome was achieved at the 1-year follow-up [22]. In 2000, Anshun et al. reported 2 cases of MCA SA for which an STA-to-MCA bypass was followed by occlusion of the internal carotid artery; a favorable outcome was achieved [26]. The details of these cases are given in Table 3.

\section{(2) Endovascular embolization}

Selected patients can be treated with endovascular approaches [46, 47]. The definite indications for endovascular embolization of SA are as follows: adequate collateral circulation as assessed by BOT. In addition, the mass effect of SA should not be severe if this procedure is to be used. This limitation arises because much time is required for SAs to gradually diminish after endovascular treatment and because acute volume increases can occur after embolization [39].

As early as 1995, Mawad et al. used endovascular embolization to treat SAs [29]. In 2001, Otsuka et al. reported 2 cases of SA: 1 case involving the A1 segment in the terminal portion of the right internal carotid artery, and 1 case arising from the vertebral artery. The aneurysms were trapped by the placement of coils after BOT. The SAs were reduced in size, and the mass effects were eliminated after surgery; good recoveries were achieved [48]. In 2004, Zicherman reported a case of SA involving the superior cerebellar artery. Proximal occlusion was performed with coil placement after an assessment of collateral circulation. A favorable outcome was achieved at the 2-month follow-up [49].

In addition to coil placement for SA embolization, coil placement plus glue is also a good option. Specifically, the glue can be trapped by the coils to avoid blocking perforating branches. In 1995, Aletich et al. reported a case of distal cerebral artery SA treated with coil placement and glue; a good outcome was achieved for this patient [22]. SA embolization using glue alone has also been reported. In 2004, Pany et al. reported a case of MCA SA treated with glue, and a favorable outcome was achieved [50]. However, cases treated with glue alone are rarely reported because glue can cause accidental embolization of normal vessels distal to the SA.

The majority of SA cases that require endovascular treatment also require a BOT. However, a BOT is not required, and the SA can be directly excised in certain cases. For example, SA arising from the P2 segment of the posterior cerebral artery can be occluded directly because of rich collateral circulation in this area; no neurological deficits have been reported in this context [51]. In 2002, Coley et al. reported 2 cases of SA in the P2 segment of the posterior cerebral artery. Coil placement was used to occlude the SA directly, and the postoperative course was uneventful. The size of the aneurysm was reduced, and the mass effect resolved at follow-up 
[52]. In 2007, Xianli et al. reported 5 cases of SAs, 3 of which were located in the P2 segment, 1 in the P1 segment, and 1 in the MCA. All of these cases were treated with direct occlusion. These cases suggested that some cases of SA can directly be occluded after a complete assessment of collateral circulation [47]. The details of these cases are given in Table 1.

\section{Complications}

SA complications include SA-related ischemia, a worsening mass effect caused by an increasing aneurysm size after embolization, relapse, and complications due to both surgery and embolization.

(1) Ischemic complications: Ischemia of the distal cerebral tissue can be best avoided with the use of BOTs to assess the blood supply of the normal brain tissue. However, ischemic complications can occasionally occur during surgery. In 2015, Pavesi et al. reported a case of MCA SA for which coils were placed to reduce the blood flow prior to surgery. However, paralysis of the extremities and neurological sequelae occurred after resection of the aneurysm and end-to-end anastomosis of the artery [39]. These complications were considered to result from ischemia caused by damage to the perforating branches of the MCA. Therefore, some researchers advocate occluding the outflow or inflow pathway but not excising the aneurysm, to protect the perforating branches that arise from the aneurysm.

(2) Increase in aneurysm size. Size increases in SAs and worsening mass effects are primarily observed in endovascular therapy because of acute thrombosis. In 2008, Van et al. reported a group of SA cases treated with endovascular embolization. In 1 case, the SA was occluded after endovascular treatment, but a partial SA resection was performed via craniotomy 10 months later due to a worsening mass effect [53]. In addition, in 2015, Krafft et al. reported a case of SA for which coils were placed to occlude the anterior cerebral artery after cross compression experiments confirmed no ischemia. The aneurysm was completely occluded after surgery, but progressive visual impairment occurred. This impairment improved by 14 months after the surgery, at which time the size of the aneurysm had gradually reduced [12]. Therefore, high-dose corticosteroids have been advocated for use before the treatment of SAs, to reduce the mass effect related to the aneurysm and to reduce the risk of neurologic insult.

(3) Relapse of SA. SA relapse is rarely reported. In 1999, Lee et al. reported 1 case of SA in the P2 segment of the posterior cerebral artery. An SA thrombosis was noted on admission, but the SA recanalized 3 weeks later with worse clinical symptoms. A good outcome was achieved after surgical treatment [54]. In 1994,
Isla et al. reported a case of MCA SA that subsided after an STA-MCA bypass and occlusion of the internal carotid artery. However, the aneurysm relapsed and regrew during a 2-year follow-up [55]. The key to SA treatment is to stop blood flow within the aneurysm, whether or not the inflow or outflow pathway or internal carotid artery is occluded. However, the risk of SA recanalization exists if the internal carotid artery is distant from the SA and other open collateral circulation. In 1994, Yoshimura et al. reported a case of SA of the carotid artery and MCA. An STA-MCA bypass and internal carotid artery occlusion were performed because of difficultly in clipping the aneurysm. The aneurysm was observed at the 5-year follow-up but relapsed 10 years after surgery, being revealed by DSA [56]. This fact re-emphasizes the importance of proximal occlusion of the SA.

\section{Summary}

Intracranial SA can be treated with surgery and endovascular embolization. However, it is necessary to assess the blood supply of normal brain tissue distal to the SA using a BOT or a cross compression test. SAs can be directly excised or embolized if the collateral circulation can sufficiently compensate. If the compensatory collateral circulation is poor, a bypass surgery is required before surgical resection or occlusion of the inflow or outflow pathway. Satisfactory outcomes can be achieved after treatment, but the size of the SA may increase after interventional treatment in some cases. Special attention should be given to cases with a significant mass effect in order to avoid the need for subsequent SA excision due to an intolerable mass effect.

\section{Competing Interests}

The authors have declared that no competing interest exists.

\section{References}

1. Segal HD, McLaurin RL. Giant serpentine aneurysm. Report of two cases. J Neurosurg. 1977; 46: 115-20.

2. Anson JA, Lawton MT, Spetzler RF. Characteristics and surgical treatment of dolichoectatic and fusiform aneurysms. J Neurosurg. 1996; 84: 185-93.

3. Choudhary P, Khokhar HV, Saxena S. Giant serpentine vertebrobasilar aneurysm with vertebral artery hypoplasia and fenestration- a case report. J Clin Diagn Res. 2015; 9: TD01-2.

4. Fodstad H, Liliequist B, Wirell S, Nilsson PE, Boquist L, Abdul-Rahman A. Giant serpentine intracranial aneurysm after carotid ligation. Case report. J Neurosurg. 1978; 49: 903-9.

5. Fanning NF, Kelleher MO, Ryder DQ. The pretzel sign: angiographic pattern of tortuous intra-aneurysmal blood flow in a giant serpentine aneurysm. Br J Neurosurg. 2003; 17: 67-71.

6. Gass A, Hennerici MG. MRI of basilar-artery-aneurysm growth. Lancet Neurol. 2003; 2: 128

7. Sharma S. Evolution of Giant P2-Posterior Cerebral Artery Aneurysm over 16 Years: Saccular to Serpentine. A Case Report. Neuroradiol J. 2009; 22: 605-11.

8. Christiano LD, Gupta G, Prestigiacomo CJ, Gandhi CD. Giant serpentine aneurysms. Neurosurg Focus. 2009; 26: E5 
9. Senbokuya N, Kanemaru K, Kinouchi H, Horikoshi T. Giant serpentine aneurysm of the distal anterior cerebral artery. J Stroke Cerebrovasc Dis. 2012; 21: 910 e7-11.

10. Suzuki S, Takahashi T, Ohkuma H, Shimizu T, Fujita S. Management of giant serpentine aneurysms of the middle cerebral artery--review of literature and report of a case successfully treated by STA-MCA anastomosis only. Acta Neurochir (Wien). 1992; 117: 23-9.

11. Day AL, Gaposchkin CG, Yu CJ, Rivet DJ, Dacey RG, Jr. Spontaneous fusiform middle cerebral artery aneurysms: characteristics and a proposed mechanism of formation. J Neurosurg. 2003; 99: 228-40.

12. Verny C, Marc G, Pasco A, Dubas F. Middle cerebral artery dissection gives rise to giant serpentine aneurysm. Cerebrovasc Dis. 2008; 25: 283-5.

13. Nakatomi H, Segawa H, Kurata A, Shiokawa Y, Nagata K, Kamiyama H, et al. Clinicopathological study of intracranial fusiform and dolichoectatic aneurysms : insight on the mechanism of growth. Stroke. 2000; 31: 896-900.

14. Vishteh AG, Spetzler RF. Evolution of a dolichoectatic aneurysm into a giant serpentine aneurysm during long-term follow up. Case illustration. J Neurosurg. 1999; 91: 346

15. Bakac G, Gholkar A, Mendelow AD. Delayed aneurysm formation following surgery for a giant serpentine aneurysm. Br J Neurosurg. 1997; 11: 260-3.

16. Huang L, Cao W, Ge L, Lu G, Wan J, Zhang L, et al. Endovascular management of giant middle cerebral artery aneurysms. Int J Clin Exp Med. 2015; 8: 7517-25.

17. Terada Y, Tomita K, Shinoda T, Iino Y, Yoshiyama N. Giant serpentine aneurysm in a long-term hemodialysis patient. Clin Nephrol. 1988; 30: 164-7.

18. Mahadevan A, Tagore R, Siddappa NB, Santosh V, Yasha TC, Ranga U, et al. Giant serpentine aneurysm of vertebrobasilar artery mimicking dolichoectasia--an unusual complication of pediatric AIDS. Report of a case with review of the literature. Clin Neuropathol. 2008; 27: 37-52.

19. Terao H, Muraoka I. Giant aneurysm of the middle cerebral artery containing an important blood channel. Case report. J Neurosurg. 1972; 37: 352-6.

20. Patel DV, Sherman IC, Hemmati M, Ferguson RJ. Giant serpentine intracranial aneurysm. Surg Neurol. 1981; 16: 402-7.

21. Sari A, Kandemir S, Kuzeyli K, Dinc H. Giant serpentine aneurysm with acute spontaneous complete thrombosis. AJNR Am J Neuroradiol. 2006; 27: 766-8.

22. Aletich VA, Debrun GM, Monsein LH, Nauta HJ, Spetzler RF. Giant serpentine aneurysms: a review and presentation of five cases. AJNR Am J Neuroradiol. 1995; 16: 1061-72.

23. Konus OL, Ilgit ET, Ozdemir A, Onal B. Spontaneous thrombosis of a vein of Galen aneurysmal malformation: possible effects of contrast media. Eur Radiol. 2000; 10: 1456-8.

24. McLaughlin N, Denis D, Bojanowski MW. Neoangiogenesis of a serpentine middle cerebral artery aneurysm. Acta Neurochir (Wien). 2012; 154: 63-4.

25. Asaithambi G, Adil MM, Chaudhry SA, Qureshi AI. Incidences of unruptured intracranial aneurysms and subarachnoid hemorrhage: results of a statewide study. J Vasc Interv Neurol. 2014; 7: 14-7.

26. Anshun W, Feng L, Daming W. Giant serpentine aneurysms: multidisciplinary management. Report of four cases and review of the literature. Interv Neuroradiol. 2000; 6: 41-52

27. Kalani MY, Zabramski JM, Nakaji P, Spetzler RF. Twenty-year follow-up of flow reversal and revascularization for a giant serpentine basilar artery aneurysm. Neurosurgery. 2014; 10 Suppl 3: E493-7; discussion E7.

28. Krafft PR, Yonas H, Carlson AP. Near-Complete Resolution of Clinical and Radiographic Findings After Endovascular Embolization of a Giant Serpentine A1 Aneurysm. World Neurosurg. 2015.

29. Mawad ME, Klucznik RP. Giant serpentine aneurysms: radiographic features and endovascular treatment. AJNR Am J Neuroradiol. 1995; 16: 1053-60.

30. Belec L, Cesaro P, Brugieres P, Gray F. Tumor-simulating giant serpentine aneurysm of the posterior cerebral artery. Surg Neurol. 1988; 29: 210-5.

31. Kobylecki C, Gerhard A, Thompson JC, Hughes D, O'Driscoll K. Giant serpentine aneurysm of the anterior cerebral artery mimicking frontotemporal dementia. J Neurol. 2013; 260: 1163-5.

32. Tsuang FY, Li CH, Chen JY, Chen TF, Tu YK. Giant serpentine aneurysm mimics cerebral arteriovenous malformation on angiography. Br J Neurosurg. 2010; 24: 716-7.

33. Horowitz MB, Yonas $\mathrm{H}$, Jungreis $\mathrm{C}$, Hung TK. Management of a giant middle cerebral artery fusiform serpentine aneurysm with distal clip application and retrograde thrombosis: case report and review of the literature. Surg Neurol. 1994; 41: 221-5.

34. Lukin RR, Chambers AA, McLaurin R, Tew J, Jr. Thrombosed giant middle cerebral aneurysms. Neuroradiology. 1975; 10: 125-9.

35. Yuan $\mathrm{YJ}, \mathrm{Xu} \mathrm{K}$, Luo Q, Yu JL. Research progress on vertebrobasilar dolichoectasia. Int J Med Sci. 2014; 11: 1039-48.

36. Esposito G, Durand A, Van Doormaal T, Regli L. Selective-targeted extra-intracranial bypass surgery in complex middle cerebral artery aneurysms: correctly identifying the recipient artery using indocyanine green videoangiography. Neurosurgery. 2012; 71: ons274-84; discussion ons84-5.

37. Tateshima S, Murayama Y, Gobin YP, Duckwiler GR, Guglielmi G, Vinuela F. Endovascular treatment of basilar tip aneurysms using Guglielmi detachable coils: anatomic and clinical outcomes in 73 patients from a single institution. Neurosurgery. 2000; 47: 1332-9; discussion 9-42.

38. Lee SJ, Ahn JS, Kwun BD, Kim CJ. Giant serpentine aneurysm of the middle cerebral artery. J Korean Neurosurg Soc. 2010; 48: 177-80.

39. Pavesi G, Dimitriadis S, Baroni S, Vallone S, Valzania F, Costella GB, et al. Intraoperative Functional and Perfusion Monitoring During Surgery for Giant
Serpentine Middle Cerebral Artery Aneurysms. World Neurosurg. 2015; 84: 592 e15-21.

40. Fukamachi A, Hirato M, Wakao T, Kawafuchi J. Giant serpentine aneurysm of the posterior cerebral artery. Neurosurgery. 1982; 11: 271-6.

41. Moon HS, Kim TS, Joo SP. Surgical treatment of giant serpentine aneurysm of A2-a3 segment distal anterior cerebral artery : technical case report. J Korean Neurosurg Soc. 2012; 52: 501-4.

42. Greene KA, Anson JA, Spetzler RF. Giant serpentine middle cerebral artery aneurysm treated by extracranial-intracranial bypass. Case report. J Neurosurg. 1993; 78: 974-8.

43. Gonzalez-Darder JM, Quilis-Quesada V, Gonzalez-Lopez P, Real-Pena L, Cortes-Donate V. [Treatment of a giant serpentine type middle cerebral artery aneurysm with a high-flow bypass from the petrous internal carotid artery]. Neurocirugia (Astur). 2011; 22: 429-33.

44. Abiko M, Ikawa F, Ohbayashi N, Mitsuhara T, Nosaka R, Inagawa T. Giant serpentine aneurysm arising from the middle cerebral artery successfully treated with trapping and anastomosis: case report. Neurol Med Chir (Tokyo). 2009; 49: 77-80

45. Amin-Hanjani S, Chen PR, Chang SW, Spetzler RF. Long-term follow-up of giant serpentine MCA aneurysm treated with EC-IC bypass and proximal occlusion. Acta Neurochir (Wien). 2006; 148: 227-8.

46. Manhas A, Nimjee SM, Agrawal A, Zhang J, Diaz O, Zomorodi AR, et al. Comprehensive Overview of Contemporary Management Strategies for Cerebral Aneurysms. World Neurosurg. 2015; 84: 1147-60.

47. Xianli L, Youxiang L, Liu A, Jiang P, Lv M, Wu Z. Endovascular treatment of intracranial giant serpentine aneurysms. Neuroradiol J. 2007; 20: 237-41.

48. Otsuka G, Miyachi S, Handa T, Negoro M, Okamoto T, Suzuki O, et al. Endovascular trapping of giant serpentine aneurysms by using Guglielmi detachable coils: successful reduction of mass effect. Report of two cases. J Neurosurg. 2001; 94: 836-40.

49. Zicherman J, Roychowdhury S, Demarco JK, Shepard S, Schonfeld S, Keller I, et al. Endovascular treatment of a ruptured giant serpentine aneurysm of the superior cerebellar artery in a patient with a Chiari II malformation. AJNR Am J Neuroradiol. 2004; 25: 1077-9.

50. Pany A, Sobri M, Valarmathi S, Latif AZ. Giant serpentine middle cerebral artery aneurysm. Med J Malaysia. 2004; 59: 422-4.

51. Lv X, Li Y, Jiang C, Yang X, Wu Z. Parent vessel occlusion for P2 dissecting aneurysms of the posterior cerebral artery. Surg Neurol. 2009; 71: 319-25, discussion 25

52. Coley SC, Hodgson TJ, Jakubowski J. Coil embolization of giant serpentine aneurysms: report of two cases arising from the posterior cerebral artery. $\mathrm{Br} \mathrm{J}$ Neurosurg. 2002; 16: 43-7.

53. van Rooij WJ, Sluzewski M, Beute GN. Endovascular treatment of giant serpentine aneurysms. AJNR Am J Neuroradiol. 2008; 29: 1418-9.

54. Lee KC, Joo JY, Lee KS, Shin YS. Recanalization of completely thrombosed giant aneurysm: case report. Surg Neurol. 1999; 51: 94-8.

55. Isla A, Alvarez F, Roda JM, Munoz J, Morales C, Garcia Blazquez M. Serpentine aneurysm: regrowth after a superficial temporal artery-middle cerebral artery bypass and internal carotid artery ligation: case report. Neurosurgery. 1994; 34: 1072-4

56. Yoshimura S, Nishimura Y, Andoh T, Sakai N, Yamada H. [Giant serpentine aneurysm followed up for more than 10 years: report of a case and review of the literature]. No Shinkei Geka. 1994; 22: 179-83. 